Eisenhardt

Textsystem Mietrecht 



\title{
Textsystem Mietrecht
}

von

\section{Thomas Eisenhardt}

\author{
Frankfurt am Main
}

2005

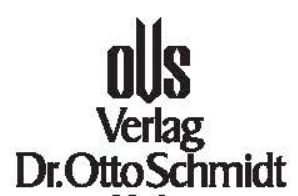

Köln 
Bibliografische Information Der Deutschen Bibliothek

Die Deutsche Bibliothek verzeichnet diese Publikation in der Deutschen Nationalbibliografie; detaillierte bibliografische Daten sind im Internet über <http://dnb.ddb.de> abrufbar.

\author{
Verlag Dr. Otto Schmidt KG \\ Gustav-Heinemann-Ufer 58, 50968 Köln \\ Tel.: 02 21/9 37 38-01, Fax: 02 21/9 37 38-9 43 \\ e-mail: info@otto-schmidt.de \\ www.otto-schmidt.de
}

ISBN 3-504-45032-0

() 2005 by Verlag Dr. Otto Schmidt KG

Das Werk einschließlich aller seiner Teile ist urheberrechtlich geschützt. Jede Verwertung, die nicht ausdrücklich vom Urheberrechtsgesetz zugelassen ist, bedarf der vorherigen Zustimmung des Verlages. Das gilt insbesondere für Vervielfältigungen, Bearbeitungen, Übersetzungen, Mikroverfilmungen und die Einspeicherung und Verarbeitung in elektronischen Systemen.

Das verwendete Papier ist aus chlorfrei gebleichten Rohstoffen hergestellt, holz- und säurefrei, alterungsbeständig und umweltfreundlich.

Umschlaggestaltung: Jan P. Lichtenford, Mettmann

Gesamtherstellung: Bercker, Kevelaer

Printed in Germany 